\title{
Analysis and discussion on the experimental data of electrolyte analyzer
}

\author{
XinYu DONG, JunJie JIANG, MengJun LIU, Weiwei LI \\ Tianjin Institute Of Metrological Supervision and Testing, Tianjin, 300192, China
}

\begin{abstract}
In the subsequent verification of electrolyte analyzer, we found that the instrument can achieve good repeatability and stability in repeated measurements with a short period of time, in line with the requirements of verification regulation of linear error and cross contamination rate, but the phenomenon of large indication error is very common, the measurement results of different manufacturers have great difference, in order to find and solve this problem, help enterprises to improve quality of product, to obtain accurate and reliable measurement data, we conducted the experimental evaluation of electrolyte analyzer, and the data were analyzed by statistical analysis.
\end{abstract}

\section{Introduction}

Electrolyte analyzer is commonly used in medical institutions at all levels. It is mainly used to detect human serum, plasma, whole blood and electrolyte ion in urine such as $\mathrm{K}^{+}, \mathrm{Na}^{+}, \mathrm{Cl}^{-}, \mathrm{Ca}^{2+}, \mathrm{pH}$ and carbon dioxide. The electrolyte analyzer uses the ion selective electrode measurement technology and the sensor technology, and uses microcomputers to realize rapid and convenient detection and data printing. The typical internal structure is shown in Figure 1.

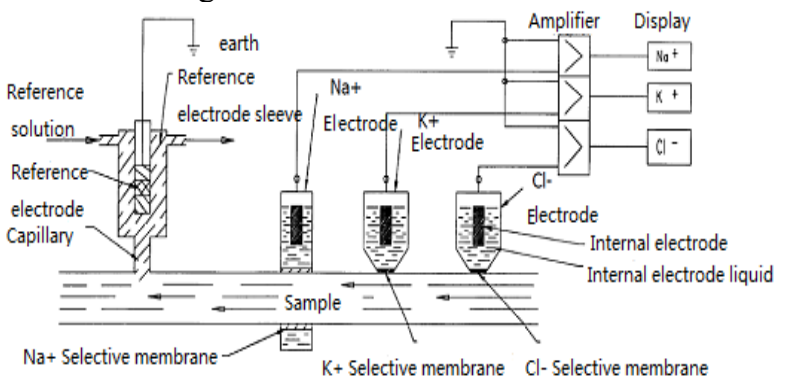

Fig. 1. The schematic diagram of the internal structure of the electrolyte analyzer

\section{Measurement Principle and Development Status}

\subsection{Measurement principle of ion selective electrode}

Ion selective electrode is a kind of electrochemical sensor. Its key component is the sensitive membrane which determines the potential response and selectivity. The sensitive membrane changes the potential by reacting with the corresponding ions in the sample. The membrane potential form a measuring cell through the liquid filled, internal reference electrode, by a wire conveying with the amplifier of high input impedance, obtained the concentration value of measured ion by calculating. The relationship between the potential of ion selective electrodes and the concentration of ions in the measured solution can be expressed by the Nernst equation, as shown in Formula 1:

$$
E=E_{0} \pm \frac{2.303 \mathrm{RT}}{\mathrm{nF}} \ln \left(\alpha_{\mathrm{i}} \mathrm{f}_{\mathrm{i}}\right)
$$

For a specific ion, at a certain temperature, $2.303 \mathrm{RT} / \mathrm{nF}$ is a certain value, then Formula 1 can be simplified as:

$$
E=E_{0}+\mathrm{S} \lg \alpha_{\mathrm{i}}
$$

From the equations above, we know that under certain experimental conditions, the potential of ionic selective electrode (E) is linearly related to the logarithm of ionic activity (or concentration) in the measured solution. In practical applications, a comparative method is used to calculate the ionic concentration of the sample solution, and the standard liquid (A calibration solution and $\mathrm{B}$ calibration solution) of two known concentrations is measured first, with the two cell electromotive force of the battery, the slope of each electrode can be calculated and a calibration curve is set up in the instrument program, then the cell electromotive force of the unknown concentration sample is measured, and the concentration of the sample ion is obtained from the calibration curve established, as shown in Figure 2. 


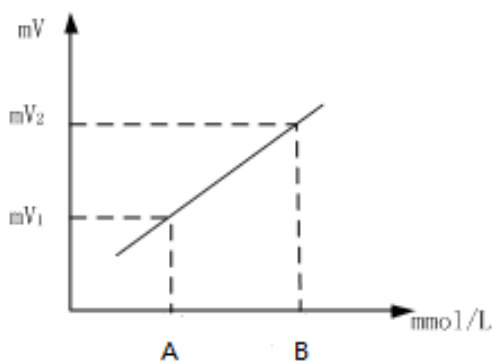

Fig. 2. Calibration curve

\subsection{Development Status}

The electrolyte analysis instrument used in China started late. In the early 1980s, a few units in China began to introduce the assembled clinical electrolyte analyzer. With the development of microelectronics and material science, the performance of electrolyte analyzer has been greatly improved, and it has been widely applied in various medical institutions and experimental institutes in China. According to incomplete statistics, there are as many as more than 30 manufacturers and companies that produce clinical electrolyte analyzer at present. The quality of products is also quite different. As a measuring instrument, it should have the metrological characteristics that conform to the standard requirements. In order to ensure the accuracy of the instrument, prevent the phenomenon that test results of patient in different hospitals, have obvious discrepancy, we need to do traceability of electrolyte analyzer, China promulgated verification regulation of electrolyte analyzer, which provide the technical basis for the quality control of the electrolyte analyzer.

\section{Analysis of Test Results}

\subsection{Test evaluation experiment}

The assessment experiment chooses three instruments , BK-2008E electrolyte analyzer made byBeijing Beiken, the latest model of URIT-910Plus electrolyte analyzer made by Guilin Uritest, the one made by German Abbott. The appearance identification of the three instruments are in line with the requirements, all of the fasteners are installed firmly, have good connection, no looseness; buttons and switches can work properly, which will not affect the normal operation of the instrument; sampling system and detection system are no leakage, no vibration and noise. This experiment using three concentrations of human serum inorganic component electrolyte standard material, the numbers are GBW (E) 090794, GBW (E) 090795, GBW (E) 090796, respectively. The potassium and sodium ions fixed values by means of atomic absorption, the chloride ion fixed values by means of ion chromatography.

\subsection{Analysis of test data}

The instruments were tested by washing, calibration and other procedures. Six times of repeated measurements were done in a short time by the same operator using the three concentrations of standard material. The repeatability of the instrument can be calculated by formula 3 and formula 4 . The test results were shown in Table 1.

$$
\begin{aligned}
& r=s / \bar{x} \times 100 \% \\
& s=\sqrt{\frac{\sum_{i=1}^{n}\left(x_{i}-\bar{x}\right)^{2}}{n-1}}
\end{aligned}
$$

\begin{tabular}{|c|c|c|c|c|c|c|c|c|c|c|c|}
\hline Model & $\begin{array}{l}\text { Standard } \\
\text { Material }\end{array}$ & Ion & $\mathrm{X}_{1}$ & $\mathrm{x}_{2}$ & $\mathrm{X}_{3}$ & $\mathrm{X}_{4}$ & $\mathrm{X}_{5}$ & $\mathrm{X}_{6}$ & $x$ & $\mathrm{~S}$ & $\begin{array}{l}r \\
(\%)\end{array}$ \\
\hline \multirow{9}{*}{$\begin{array}{c}\text { BK- } \\
2008 \mathrm{E}\end{array}$} & \multirow{3}{*}{$\begin{array}{r}\text { GBW（E） } \\
090794\end{array}$} & $\mathrm{~K}^{+}$ & 6.75 & 6.74 & 6.71 & 6.67 & 6.71 & 6.72 & 6.72 & 0.03 & 0.4 \\
\hline & & $\mathrm{Na}^{+}$ & 115.63 & 114.91 & 114.91 & 114.91 & 114.67 & 114.43 & 114.91 & 0.4 & 0.4 \\
\hline & & $\mathrm{Cl}^{-}$ & 82.84 & 82.43 & 82.43 & 82.84 & 82.43 & 82.43 & 82.57 & 0.21 & 0.3 \\
\hline & \multirow{3}{*}{$\begin{array}{r}\text { GBW（E） } \\
090795\end{array}$} & $\mathrm{~K}^{+}$ & 4.14 & 4.15 & 4.15 & 4.15 & 4.16 & 4.14 & 4.15 & 0.01 & 0.2 \\
\hline & & $\mathrm{Na}^{+}$ & 140.58 & 140.58 & 140.58 & 140.88 & 142.05 & 141.75 & 141.07 & 0.66 & 0.5 \\
\hline & & $\mathrm{Cl}^{-}$ & 107.71 & 107.71 & 107.71 & 107.71 & 105.6 & 106.12 & 107.09 & 0.97 & 0.9 \\
\hline & \multirow{3}{*}{$\begin{array}{r}\text { GBW（E） } \\
090796\end{array}$} & $\mathrm{~K}^{+}$ & 2.1 & 2.09 & 2.05 & 2.11 & 2.06 & 2.11 & 2.09 & 0.03 & 1.2 \\
\hline & & $\mathrm{Na}^{+}$ & 157.94 & 157.29 & 156.96 & 155.98 & 156.3 & 155.66 & 156.69 & 0.86 & 0.6 \\
\hline & & $\mathrm{Cl}^{-}$ & 140.75 & 142.15 & 143.57 & 143.57 & 144.99 & 144.28 & 143.22 & 1.53 & 1.1 \\
\hline \multirow{7}{*}{$\begin{array}{l}\text { URIT- } \\
\text { 910Plus }\end{array}$} & \multirow{3}{*}{$\begin{array}{r}\text { GBW（E） } \\
090794\end{array}$} & $\mathrm{~K}^{+}$ & 6.89 & 6.71 & 6.9 & 6.67 & 6.91 & 6.9 & 6.83 & 0.11 & 1.6 \\
\hline & & $\mathrm{Na}^{+}$ & 103.3 & 104.1 & 103.4 & 104.7 & 103.6 & 103.6 & 103.8 & 0.5 & 0.5 \\
\hline & & $\mathrm{Cl}^{-}$ & 91.31 & 92.02 & 91.66 & 92.19 & 91.49 & 91.84 & 91.75 & 0.33 & 0.4 \\
\hline & \multirow{3}{*}{$\begin{array}{r}\text { GBW (E) } \\
090795\end{array}$} & $\mathrm{~K}^{+}$ & 4.12 & 4.12 & 4.12 & 4.12 & 4. 12 & 4.13 & 4.12 & 0 & 0.1 \\
\hline & & $\mathrm{Na}^{+}$ & 137.5 & 137.8 & 137.8 & 138 & 137.8 & 138.3 & 137.9 & 0.3 & 0.2 \\
\hline & & $\mathrm{Cl}^{-}$ & 105.8 & 105.8 & 106 & 106 & 106 & 106.3 & 106 & 0.2 & 0.2 \\
\hline & GBW (E) & $\mathrm{K}^{+}$ & 1.97 & 1.94 & 1.94 & 1.95 & 1.95 & 1.95 & 1.95 & 0.01 & 0.6 \\
\hline
\end{tabular}

Table 1. Results of repeatability measurement 


\begin{tabular}{|c|c|c|c|c|c|c|c|c|c|c|c|}
\hline & \multirow[t]{2}{*}{090796} & $\mathrm{Na}^{+}$ & 156.2 & 155.9 & 155.6 & 155.6 & 155.6 & 155.4 & 155.7 & 0.29 & 0.2 \\
\hline & & $\mathrm{Cl}^{-}$ & 129.5 & 129.3 & 129.3 & 129.3 & 129.5 & 129.5 & 129.4 & 0.11 & 0.1 \\
\hline \multirow{9}{*}{ Abbott } & \multirow{3}{*}{$\begin{array}{r}\text { GBW (E) } \\
090794\end{array}$} & $\mathrm{~K}^{+}$ & 6.5 & 6.5 & 6.6 & 6.6 & 6.6 & 6.5 & 6.6 & 0.1 & 0.8 \\
\hline & & $\mathrm{Na}^{+}$ & 107 & 108 & 107 & 107 & 107 & 107 & 107.2 & 0.4 & 0.4 \\
\hline & & $\mathrm{Cl}^{-}$ & 100 & 101 & 101 & 102 & 101 & 102 & 101.2 & 0.8 & 0.7 \\
\hline & \multirow{3}{*}{$\begin{array}{r}\text { GBW (E) } \\
090795\end{array}$} & $\mathrm{~K}^{+}$ & 4.3 & 4.0 & 4.1 & 4.0 & 4.1 & 4.1 & 4.1 & 0.10 & 2.70 \\
\hline & & $\mathrm{Na}^{+}$ & 141 & 141 & 141 & 141 & 142 & 141 & 141.17 & 0.4 & 0.3 \\
\hline & & $\mathrm{Cl}^{-}$ & 108 & 108 & 108 & 109 & 109 & 109 & 108.5 & 0.5 & 0.5 \\
\hline & \multirow{3}{*}{$\begin{array}{r}\text { GBW（E） } \\
090796\end{array}$} & $\mathrm{~K}^{+}$ & $<2.0$ & $<2.0$ & $<2.0$ & $<2.0$ & $<2.0$ & $<2.0$ & 1 & 1 & 1 \\
\hline & & $\mathrm{Na}^{+}$ & 159 & 160 & 159 & 159 & 160 & 160 & 159.5 & 0.5 & 0.3 \\
\hline & & $\mathrm{Cl}^{-}$ & 131 & 131 & 132 & 130 & 132 & 132 & 131.3 & 0.8 & 0.6 \\
\hline
\end{tabular}

By the repeatability measurement, the indication error of the instruments at three concentrations can be obtained. The indication error can be calculated by

$$
\delta=\frac{\bar{x}-\mathrm{D}}{\mathrm{D}} \times 100 \%
$$
formula 5 , and the results were shown in Table 2 .

Table 2. Measurement results of the indication error

\begin{tabular}{|c|c|c|c|c|c|c|}
\hline \multirow{2}{*}{ Model } & \multirow{2}{*}{$\begin{array}{l}\text { Standard } \\
\text { Material }\end{array}$} & \multirow{2}{*}{ Ion } & \multirow{2}{*}{$\begin{array}{l}\text { Standard } \\
\text { Value } \\
\left(\mathrm{mmol} \cdot \mathrm{L}^{-1}\right)\end{array}$} & \multirow{2}{*}{$\begin{array}{c}\text { Measured } \\
\text { Value } \\
\left(\begin{array}{c}\mathrm{mmol} \cdot \mathrm{L}^{-} \\
1\end{array}\right)\end{array}$} & \multicolumn{2}{|c|}{ Indication Error } \\
\hline & & & & & $\begin{array}{l}\text { Absolute Value } \\
\quad\left(\mathrm{mmol} \cdot \mathrm{L}^{-1}\right)\end{array}$ & $\begin{array}{c}\text { Relative } \\
\text { Value }(\%)\end{array}$ \\
\hline \multirow{9}{*}{ BK-2008E } & \multirow{3}{*}{$\begin{array}{c}\text { GBW } \\
(\mathrm{E}) \\
090794\end{array}$} & $\mathrm{~K}^{+}$ & 7.02 & 6.72 & -0.30 & $-4.3 \%$ \\
\hline & & $\mathrm{Na}^{+}$ & 110.7 & 114.91 & 4.21 & $3.8 \%$ \\
\hline & & $\mathrm{Cl}^{-}$ & 99 & 82.57 & -16.43 & $-16.6 \%$ \\
\hline & \multirow{3}{*}{$\begin{array}{c}\text { GBW } \\
(\mathrm{E}) \\
090795\end{array}$} & $\mathrm{~K}^{+}$ & 4.41 & 4.15 & -0.26 & $-5.9 \%$ \\
\hline & & $\mathrm{Na}^{+}$ & 146.9 & 141.07 & -5.83 & $-4.0 \%$ \\
\hline & & $\mathrm{Cl}^{-}$ & 113.2 & 107.09 & -6.11 & $-5.4 \%$ \\
\hline & \multirow{3}{*}{$\begin{array}{c}\text { GBW } \\
(\mathrm{E}) \\
090796\end{array}$} & $\mathrm{~K}^{+}$ & 1.914 & 2.09 & 0.17 & $9.0 \%$ \\
\hline & & $\mathrm{Na}^{+}$ & 161.7 & 156.69 & -5.01 & $-3.1 \%$ \\
\hline & & $\mathrm{Cl}^{-}$ & 133.5 & 143.22 & 9.72 & $7.2 \%$ \\
\hline \multirow{9}{*}{$\begin{array}{l}\text { URIT- } \\
\text { 910Plus }\end{array}$} & \multirow{3}{*}{$\begin{array}{c}\text { GBW } \\
(\mathrm{E}) \\
090794\end{array}$} & $\mathrm{~K}^{+}$ & 7.02 & 6.83 & -0.19 & $-2.7 \%$ \\
\hline & & $\mathrm{Na}^{+}$ & 110.7 & 103.8 & -6.9 & $-6.3 \%$ \\
\hline & & $\mathrm{Cl}^{-}$ & 99 & 91.75 & -7.25 & $-7.3 \%$ \\
\hline & \multirow{3}{*}{$\begin{array}{c}\text { GBW } \\
(\mathrm{E}) \\
090795\end{array}$} & $\mathrm{~K}^{+}$ & 4.41 & 4.12 & -0.29 & $-6.5 \%$ \\
\hline & & $\mathrm{Na}^{+}$ & 146.9 & 137.9 & -9 & $-6.2 \%$ \\
\hline & & $\mathrm{Cl}^{-}$ & 113.2 & 106 & -7.2 & $-6.4 \%$ \\
\hline & \multirow{3}{*}{$\begin{array}{c}\text { GBW } \\
(\mathrm{E}) \\
090796\end{array}$} & $\mathrm{~K}^{+}$ & 1.914 & 1.95 & 0.04 & $1.9 \%$ \\
\hline & & $\mathrm{Na}^{+}$ & 161.7 & 155.7 & -6 & $-3.7 \%$ \\
\hline & & $\mathrm{Cl}^{-}$ & 133.5 & 129.4 & -4.1 & $-3.1 \%$ \\
\hline \multirow{9}{*}{$\begin{array}{c}\text { Abbott } \\
\text { (Germany) }\end{array}$} & \multirow{3}{*}{$\begin{array}{c}\text { GBW } \\
(E) \\
090794\end{array}$} & $\mathrm{~K}^{+}$ & 7.02 & 6.6 & -0.5 & $-6.7 \%$ \\
\hline & & $\mathrm{Na}^{+}$ & 110.7 & 107.2 & -3.5 & $-3.2 \%$ \\
\hline & & $\mathrm{Cl}^{-}$ & 99 & 101.2 & 2.2 & $2.2 \%$ \\
\hline & \multirow{3}{*}{$\begin{array}{c}\text { GBW } \\
(E) \\
090795\end{array}$} & $\mathrm{~K}^{+}$ & 4.41 & 4.1 & -0.3 & $-7.0 \%$ \\
\hline & & $\mathrm{Na}^{+}$ & 146.9 & 141.17 & -5.7 & $-3.9 \%$ \\
\hline & & $\mathrm{Cl}^{-}$ & 113.2 & 108.5 & -4.7 & $-4.2 \%$ \\
\hline & \multirow{3}{*}{$\begin{array}{c}\text { GBW } \\
(\mathrm{E}) \\
090796\end{array}$} & $\mathrm{~K}^{+}$ & 1.914 & 1 & 1 & 1 \\
\hline & & $\mathrm{Na}^{+}$ & 161.7 & 159.5 & -2.2 & $-1.4 \%$ \\
\hline & & $\mathrm{Cl}^{-}$ & 133.5 & 131.3 & -2.2 & $-1.6 \%$ \\
\hline
\end{tabular}

All of the three instruments have good repeatability, which conform to the requirements for the repeatability of the verification regulation of the electrolyte analyzer. The problem is under the same test conditions, the results of three instruments were quite different by the same batch of standard material. The indication errors were all significantly higher than the technical specifications of $4 \%$.

Value error of measurement using the standard substances made by Shenzhen Kate biological medical 
electronic technology co.LTD, which were numbered GBW (E) 090794, GBW (E) 090795, GBW (E) 090796 of three kinds of human serum inorganic electrolyte standard substances, whose characteristic value and uncertainty were shown as table 3 .

Table 3. The characteristic and uncertainty of the human serum inorganic component electrolyte standard material

\begin{tabular}{|c|c|c|c|c|c|c|c|}
\hline \multirow[b]{2}{*}{ Name } & \multirow{2}{*}{$\begin{array}{c}\text { Serial } \\
\text { number }\end{array}$} & \multirow{2}{*}{$\begin{array}{c}\text { Standard value and } \\
\text { uncertainty }\end{array}$} & \multicolumn{5}{|c|}{ Concentrations $(\mathrm{mm} / \mathrm{L})$} \\
\hline & & & $\mathrm{K}^{+}$ & $\mathrm{Na}^{+}$ & $\mathrm{Cl}^{-}$ & $\mathrm{Li}^{+}$ & $\mathrm{iCa}^{2+}$ \\
\hline \multirow{6}{*}{$\begin{array}{c}\text { Human } \\
\text { serum } \\
\text { inorganic } \\
\text { component } \\
\text { electrolyte } \\
\text { standard } \\
\text { material }\end{array}$} & \multirow{2}{*}{$\begin{array}{c}\text { GBW(E)090 } \\
794\end{array}$} & Standard value & 7.02 & 110.7 & 99.0 & 1.991 & 1.528 \\
\hline & & uncertainty & 0.16 & 3.1 & 2.8 & 0.060 & 0.064 \\
\hline & \multirow{2}{*}{$\begin{array}{c}\text { GBW(E)090 } \\
795 \\
\end{array}$} & Standard value & 4.41 & 146.9 & 113.2 & 1.244 & 1.051 \\
\hline & & uncertainty & 0.11 & 2.6 & 3.2 & 0.036 & 0.025 \\
\hline & \multirow{2}{*}{$\begin{array}{c}\mathrm{GBW}(\mathrm{E}) 090 \\
796\end{array}$} & Standard value & 1.914 & 161.7 & 133.5 & 0.655 & 0.650 \\
\hline & & uncertainty & 0.056 & 3.2 & 3.7 & 0.025 & 0.020 \\
\hline
\end{tabular}

MPE requirement of Verification regulation for $\mathrm{K}^{+}$, $\mathrm{Na}^{+}$and $\mathrm{Cl}^{-}$is $\pm 4.0 \%$, according to the above-mentioned conclusion $\mathrm{MPEV} / \mathrm{U}_{95}$ is less than 3, the influence of the measurement uncertainty of error value must be considered in the assessment. The eligibility criteria are: $|\Delta| \leq$ MPEV $-\mathrm{U}_{95} \quad$ Convicted for qualified
$|\Delta| \geq \mathrm{MPEV}+\mathrm{U}_{95} \quad$ Disqualify

MPEV - $\mathrm{U}_{95}\left\langle|\Delta|\left\langle\mathrm{MPEV}+\mathrm{U}_{95}\right.\right.$ Undetermined

It can be obtained by calculation which is shown in Table 4.

Table 4. Conformance determination of indication error

\begin{tabular}{|c|c|c|c|c|}
\hline \multirow{2}{*}{ Evaluation instrument } & \multirow{2}{*}{ Serial number } & \multicolumn{3}{|c|}{ Indication error(mmol/L) } \\
\hline & & $\mathrm{K}^{+}$ & $\mathrm{Na}^{+}$ & $\mathrm{Cl}^{-}$ \\
\hline \multirow{9}{*}{ BK-2008E } & GBW(E)090794 & -0.30 & 4.21 & -16.43 \\
\hline & MPEV & 0.28 & 4.43 & 3.96 \\
\hline & Conclusions & Undetermined & Undetermined & Disqualify \\
\hline & GBW(E)090795 & -0.26 & -5.83 & -6.11 \\
\hline & MPEV & 0.18 & 5.88 & 4.53 \\
\hline & Conclusions & Undetermined & Undetermined & Undetermined \\
\hline & GBW(E)090796 & 0.17 & -5.01 & 9.72 \\
\hline & MPEV & 0.077 & 6.47 & 5.34 \\
\hline & Conclusions & Undetermined & Undetermined & Disqualify \\
\hline \multirow{9}{*}{ URIT-910Plus } & GBW(E)090794 & -0.19 & -6.9 & -7.25 \\
\hline & MPEV & 0.28 & 4.43 & 3.96 \\
\hline & Conclusions & Undetermined & Undetermined & Disqualify \\
\hline & GBW(E)090795 & -0.29 & -9.0 & -7.2 \\
\hline & MPEV & 0.18 & 5.88 & 4.53 \\
\hline & Conclusions & Disqualify & Disqualify & Undetermined \\
\hline & GBW(E)090796 & 0.04 & -6.0 & -4.1 \\
\hline & MPEV & 0.077 & 6.47 & 5.34 \\
\hline & Conclusions & Undetermined & Undetermined & Undetermined \\
\hline \multirow{9}{*}{ Abbott(Germany) } & GBW(E)090794 & -0.5 & -3.5 & 2.2 \\
\hline & MPEV & 0.28 & 4.43 & 3.96 \\
\hline & Conclusions & Disqualify & Undetermined & Undetermined \\
\hline & GBW(E)090795 & -0.3 & -5.7 & -4.7 \\
\hline & MPEV & 0.18 & 5.88 & 4.53 \\
\hline & Conclusions & Undetermined & Undetermined & Undetermined \\
\hline & GBW(E)090796 & 1 & -2.2 & -2.2 \\
\hline & MPEV & 0.077 & 6.47 & 5.34 \\
\hline & Conclusions & 1 & Qualified & Undetermined \\
\hline
\end{tabular}


Through the evaluation of uncertainty we found that the uncertainty caused by the inaccuracy of the fixed value is too large, even more than the maximum indication error of the instrument, has caused many test conclusion can only be "undetermined", which creates a big difficulty for quantity traceability of electrolyte analyzer

\section{Discussions and Conclusions}

Such problems are often encountered in daily life, the patient was treated in a hospital and tested, to another hospital for reexamination, the results of the tests are very different, it is also confirmed by the above experimental data. How to achieve the mutual recognition of different medical structures, improve the quality of instruments and equipment, save patients from repeated tests, and save medical costs for patients, which is the ultimate goal of this topic.

At present, the accuracy and reliability of clinical testing, traceability of clinical analysis of test results have gained wide attention in many countries, many countries have developed a large amount of clinical standard material, clinical laboratory reference system has also been enriched and developed, and gradually getting mature and perfect. According to the measurement principle of electrolyte analyzer, the system should be calibrated before the sample is measured, A, B standard solution are used as the calibration of ion selective electrodes with two kinds of known ionic concentration. It is assumed that the potential of $\mathrm{A}$ and $\mathrm{B}$ standard solution is $\mathrm{EA}$ and $\mathrm{EB}$ respectively, the ionic concentration is $\mathrm{CA}$ and $\mathrm{CB}$, and the electrode slope is S. According to the measured potential value and the known ion concentration value, the actual slope of each electrode can be calculated by formula 6 .

$$
\mathrm{S}=\frac{\mathrm{E}_{\mathrm{B}}-\mathrm{E}_{\mathrm{A}}}{\lg \left(\mathrm{C}_{\mathrm{B}}\right)-\lg \left(\mathrm{C}_{\mathrm{A}}\right)}=\frac{\mathrm{E}_{\mathrm{B}}-\mathrm{E}_{\mathrm{A}}}{\lg \left(\mathrm{C}_{\mathrm{B}} / \mathrm{C}_{\mathrm{A}}\right)}
$$

Assuming that the potential of the sample is EX and the ionic concentration is $\mathrm{Cx}$, the value of $\mathrm{S}$ remains unchanged under the same A and B standard solution, so that the ionic concentration $\mathrm{Cx}$ can be calculated according to the formula 7,8 .

$$
\begin{aligned}
& S=\frac{E_{x}-E_{A}}{\lg \left(C_{x} / C_{A}\right)} \\
& C_{X}=10^{\frac{E_{X}-E_{A}}{S}} C_{A}
\end{aligned}
$$

However, each manufacturer use their own A, B standard solution and ion selective electrode, the value of the standard solution is not unified, the difference in concentration of standard solution and accuracy of indication will lead to different results. In addition, the performance gap of ion selective electrodes, which have different ability of Nernst response, commonly result in the difference of the measurement results by the various manufacturers, such as shown in figure 3 .

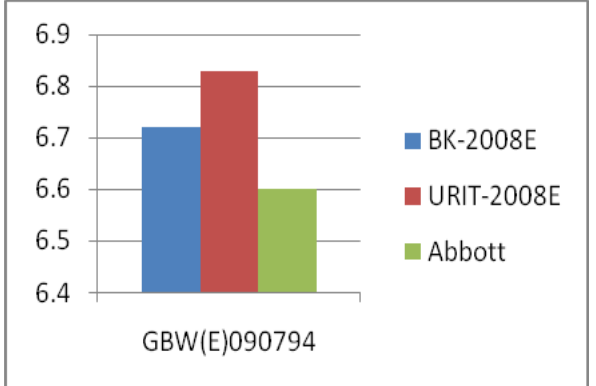

Figure. 3. Comparison of $\mathrm{K}^{+}$measurement results

In conclusion, we should develop clinical test standard substances with high quality as soon as possible, the value of the standard liquid used by the manufacturer should be traced to the unified value, manufacturer should also improve the performance of the ion selective electrode, quantity comparison can be carried out on a regular basis, in order to realize the unification of the quantity value, the quantity value of the electrolyte analyzer is ensured to be accurate and reliable.

\section{References}

1. Ding Haiming, Wu Guoqiang. "Electrolyte analysis and measurement techniques", Beijing: China Metrology Publishing House, 2009: (128-131).

2. Ding Haiming, Wu Guoqiang. "JJG1051-2009 Verification Regulation for Electrolyte Analyzer”. 